\title{
Parsimonious Determinants of Pre-Incubated Academic Spin-Offs Initial Performance: a Configurational Perspective
}

\author{
Jonathan Simões Freitas', Carlos Alberto Gonçalves², Lin Chih Cheng ${ }^{3}$, Reynaldo Maia Muniz ${ }^{4}$
}

\begin{abstract}
The aim of this paper is to refine, from a configurational perspective, the understanding of causal conditions underlying performance differences between new academic technology-based firms. Qualitative comparative analysis (QCA), a research strategy conceived to investigate parsimonious configurations that explain a given result of interest in small-N populations, was adopted as the methodological approach. The analyses were performed using a database related to $8 \mathrm{I}$ Brazilian academic spin-offs, pre-incubated by a governmental innovation promotion program. Based on the resultant configurations, parsimonious sets of variables for explaining the initial performance of these new ventures were obtained. Complementary findings and their respective implications are also discussed.
\end{abstract}

Keywords: (QCA) qualitative comparative analysis; organizational performance; academic spin-offs; configurational perspective.

\footnotetext{
' PhD Student. Centre of Post-Graduation and Research in Management, School of Economic Sciences, Federal University of Minas Gerais (UFMG). Antônio Carlos Avenue, 6627, Pampulha, Belo Horizonte, Minas Gerais, Brazil, 31270-90I. Tel.: +55 31 8768-6874.

Email: jonathan.ufmg@gmail.com

${ }^{2}$ Associate Professor. Department of Administrative Sciences, School of Economic Sciences, Federal University of Minas Gerais (UFMG). Antônio Carlos Avenue, 6627, Pampulha, Belo Horizonte, Minas Gerais, Brazil, 31 270-901.Tel.: +55 31 3279-7040. Email: carlos@face.ufmg.br ${ }^{3}$ Associate Professor. Department of Production Engineering, School of Engineering, Federal University of Minas Gerais (UFMG).Antônio Carlos Avenue, 6627, Pampulha, Belo Horizonte, Minas Gerais, Brazil, 3 I 270-90I.Tel.: +55 31 3409-4903. Email: lincheng@dep.ufmg.br ${ }^{4}$ School Director and Associate Professor. Department of Administrative Sciences, School of Economic Sciences, Federal University of Minas Gerais (UFMG). Antônio Carlos Avenue, 6627, Pampulha, Belo Horizonte, Minas Gerais, Brazil, 31270-90I. Tel.: +55 3 I $3409-7003$. Email: munizd.bh@terra.com.br
} 


\section{Introduction}

Finding determinants of differences in organizational performance emerged as the central tenet of strategic management inquiry (Herrmann, 2005; Hoskisson et al., 1999; Mahoney and McGahan, 2007; Mellahi and Sminia, 2009). In this field, the aim to identify structures and processes underlying the heterogeneity in firm performance reconciles the various strands of research, which hold this shared objective in spite of minor conceptual divergences. Therefore, multiple theoretical approaches were established by focusing on different elements to explain the success of some companies and the failure of others (Gonçalves et al., 2009).

However, despite this rich diversity, the way in which the relation between these dimensions and the performance of firms has been investigated is still limited in several aspects (Greckhammer et al., 2008). Relationships between organizational performance and other variables taken into consideration have been assessed, in general, through linear statistical methodologies. These are based on the analysis of contingent relations between each variable independent isolated effect, restricting explanatory power and leading, sometimes, to contradictory findings (Hutzschenreuter and Kleindiest, 2006). In order to tackle this problem, there is a clear demand for researchers to adopt a configurational perspective: "Reality is too complex to be explained by simple bivariate relationships. In contrast, incorporating configurational frameworks in empirical research could increase the variance explicated" (Hutzschenreuter and Kliendienst, 2006, p. 705).

In this context, the word "configuration" means - in accordance with configurational theory - a multidimensional constellation of conceptually distinct characteristics which commonly occur together (Meyer, Tsui and Hinings, 1993). Thus, what is being argued is that this notional device focused on the study of combined effects, may help to overcome the limitations of traditional contingent approaches in what regards both the amount of variables included and, mainly, the analysis of the way in which these dimensions behave together (Hutzschenreuter and Kliendienst, 2006). The adoption of the configurational paradigm to investigate constellations of variables which may be determinant to organizational performance is, therefore, a promising avenue for the development of this area of research.

From this perspective, searching for configurations which explain the performance of academic spin-offs (ASOs) is especially relevant. Highlighted theoretical and empirical importance has been attributed to this specific type of firm' due to its singularities as a research object (e.g. Granstrand, 1998; Mustar et al., 2006; Vohora, Wright and Lockett, 2004) and to the notable evidences of its impact on regional socioeconomic development (e.g. Roberts and Eesley, 2009)2.

Understanding the causal conditions associated specifically to the initial performance of these organizations during their pre-incubation stage is, in this context, particularly significant. This performance - evaluated in terms of capacity to obtain new resources (financial and managerial) in order to finalize initial venture development (technological and commercial) and to begin market transactions depends on the firm's entry and initial expansion success. Therefore, being successful at pre-incubation is a critical factor for the effective birth and development of these important organizations (Ndonzuau, Pirnay and Surlemont, 2002; Vohora et al., 2004).

In fact, some papers have been published aiming to identify the determinants of this initial performance of preincubated academic spin-offs (PIASOs) - for a review, see Coelho (2008). However, in none of them the configurational perspective was adopted as a paradigm. Hence, it was not found in the related literature neither a methodological treatment to tackle the causal complexity resul-

\footnotetext{
' Defined, in this paper, as technology transfer in the form of a new company from an academic institution, comprising or not the involvement by the inventor in the management of the new venture and including firms in formation (Nicolaou, N., Birley, S. (2003). Academic networks in a trichotomous categorization of university spinouts. Journal of Business Venturing, 18(3), 333-359).

${ }^{2}$ Roberts and Eesley (2009) report, for example, that, if the spin-offs from the Massachusetts Institute of Technology (MIT) - approximately 25,800 enterprises up to 2009 - were considered as the productive economic units of an independent country, these companies would make this nation the Ilth world economy, generating 3.3 million jobs and 2 trillion dollars in annual income.
}

ISSN: 07 I8-2724. (http://www.jotmi.org) 
tant of combined effects nor any work on parsimonious configurations for explaining the success and failure of these organizations. This paper aims to explore this gap.

Therefore, the following research question was proposed: "under a configurational perspective, which are the parsimonious determinants of pre-incubated academic spin-offs initial performance?" Thus, the paper's general objective is to find parsimonious configurational conditions that explain heterogeneity in the initial performance of PIASOs. In addition, the specific objectives are to characterize the causal complexity of obtained solutions and to critically assess the set of causal attributes suggested by related academic literature.

\section{Theoretical Background}

The field of strategic management has been historically divided in two main strands of research (Herrmann, 2005; Hoskisson et al., 1999; Mahoney and McGahan, 2007; Mellahi and Sminia, 2009). The first, called "strategy content", encompasses all research work which emphasizes external (e.g. institutional and industrial context) and internal structures (e.g. resources) as the main determinants of firm conduct and, consequently, of its performance. The second, called "strategy process", comprises studies which highlight the agents and the way they form strategy over time as the main explicative variables for organizational performance heterogeneity.

Hence, the paradigms established by the "structure, conduct and performance" framework - with its emphasis on structures external to the company - and by the resource-based view (RBV) - with its focus on internal structures - are considered the two basic theoretical platforms on which the strategy content strand relies. On the other hand, seminal work such as that of Mintzberg (1973), oriented towards investigating the strategy formation process and its effects on firm success and failure, are considered classic theoretical references of the mainstream research on strategy process.

Thus, Porterian school and its ramifications and, subsequently, Penrosean tradition and its influence through works such as those of Wernerfelt (1984) and Barney (1991) represent the foundations of the strategy content strand. Similarly, the development of the conception presented by Mintzberg and Waters (1985) until the appearance of the "strategy-as-practice" approach (Whittington, 1996) indicates the broad theoretical spectrum of process research.
In the academic literature dedicated to the ASO phenomenon, the influence of these two main strategic management research traditions is explicit. Mustar et al. (2006), for example, identified, in a broad review of publications related to this specific type of firm, three main dimensions underlying the heterogeneity of these companies: the institutional contexts in which they are embedded, the resource structures at their disposal and the business model they adopt. It can be noticed that the first two dimensions reflect the focus of strategy content research, with its emphasis on structural elements external and internal to the company. Nevertheless, the last dimension, related to the formulation and continuous reformulation of the firm's business model, reinforces aligned with the dynamic perspective characteristic of the strategy process strand - the role of the agent and of agency in creating differences between organizations.

This theoretical influence on the study of ASOs was explicitly recognized in some recent and broad literature reviews which aimed to identify the main trends in this new field of research (e.g. Djokovic and Souitaris, 2008; O'Shea, Chugh and Allen, 2008; Rothaermel, Agung and Jiang, 2007). The investigation of the determinants of performance differences among academic spin-offs, throughout their various development phases, has been pointed out as a prominent research strand. Some of the main objectives of these investigations are to characterize the stages of development of this type of firm, the main barriers and difficulties to overcome in each of these phases and the behavior of some aspects of the new venture throughout its evolution (Djokovic and Souitaris, 2008; O'Shea et al., 2008).

Specifically in what regards pre-incubation (i.e. the phase previous to firm launching), Ndonzuau et al. (2002) point out the attainment of an initial investment for developing the business ideas and product prototypes as one of the main difficulties found by academic spin-offs in finalizing the new venture project. Accordingly, Vohora et al. (2004) emphasize the inability to attract initial financial and managerial resources as one of the main causes for the uprising of critical junctures before the company's entry and expansion in the market. Therefore, the capacity to generateenoughcredibility tobeabletoaccessthird-parties' resources in order to begin transacting with potential clients is pointed as critical for the ASO development. 
The main publications which indicate potential determinants of the ASOs' initial performance differences in the preincubation phase are some papers related to the decisive factors in the initial investment on high-tech start-ups (e.g. Kakati, 2003; Knight, 1994; MacMillan, 1985; Song et al., 2008; Zacharakis and Meyer, 2000). From work such as these, it is possible to have an overview of research dedicated to this topic and, thus, to identify the most indicated variables in academic literature to be treated as determinants of the capacity of these embryonic firms to obtain resource inputs (financial and managerial) to finalize development (technological and commercial) and launch the new venture.

For being based on the main precedent publications (and having supplied the foundation for most of the subsequent ones) and for being identified as particularly relevant criteria for the assessment of academic technologybased firms' projects in the context of initial investment decision, the eight variables of the model presented by De Coster and Butler (2005) represent the main reference in what specifically regards determinants of PIASOs initial performance (Figure I).

\begin{tabular}{|l|l|}
\hline \multicolumn{1}{|c|}{ Criterion } & \multicolumn{1}{c|}{ Objective } \\
\hline $\begin{array}{l}\text { Technological and commercial } \\
\text { risk }\end{array}$ & $\begin{array}{l}\text { Assess the effectiveness of the product concept and the viability of its } \\
\text { production }\end{array}$ \\
\hline Level of product innovation & $\begin{array}{l}\text { Assess the level of product innovation and the level of competition in the } \\
\text { market }\end{array}$ \\
\hline $\begin{array}{l}\text { Way of satisfying the market } \\
\text { sector }\end{array}$ & $\begin{array}{l}\text { Assess how the product/service satisfies the demand of a given market } \\
\text { sector and how big this market is }\end{array}$ \\
\hline Timeliness & $\begin{array}{l}\text { Assess the target-market timeliness, in relation to the relevant } \\
\text { macroeconomic conditions }\end{array}$ \\
\hline Longevity and repeatability & Assess purchasing repeatability and product longevity \\
\hline Existence of family of products & $\begin{array}{l}\text { Assess whether the technology may be incorporated, not only into one single } \\
\text { product, but to a whole product family, in order to foster the firm's future } \\
\text { development }\end{array}$ \\
\hline Entrepreneurial background & Assess the project team and its previous involvement with innovation \\
\hline $\begin{array}{l}\text { Protection of competitive } \\
\text { advantage }\end{array}$ & $\begin{array}{l}\text { Assess the intellectual property level of the technology and the products } \\
\text { developed or in development }\end{array}$ \\
\hline
\end{tabular}

Figure I. Determinants of the initial performance of PIASOs according to the model proposed by De Coster and Butler (2005). Elaborated by the authors.

Having established this theoretical background, we report, in the next section, the procedures performed in order to achieve the objectives which were proposed for the research. 


\section{Methodology}

The research consisted in adopting the qualitative comparative analysis (QCA) to analyze a database related to 81 Brazilian academic spin-offs pre-incubated by the “Innovation Promotion Program" (known as "PII"). Initially, the necessary definitions for building the property space ${ }^{3}$ were made, and, afterwards, configurational analyses were performed, both from a contextual focus and a generalist one.

\section{The Qualitative Comparative Analysis}

The qualitative comparative analysis ${ }^{4}, \mathrm{QCA}$, was proposed by Ragin (1987) as a methodological approach to, in "small-N"5 population studies, preserve cases' integrity as complex causal configurations ${ }^{6}$ and systematically examine similarities and differences in the causal factors across various cases. The interest in capturing the rich complexity of each case and, concurrently, in producing a certain level of generalization of the obtained conclusions is, therefore, the main motivation underlying QCA (Ragin, 1987).

In order to achieve the objective of analyzing causality taking into account the complexity of causal nexus, QCA is founded on a conception of causality as multiple and context-dependent (Rihoux, 2006), supported by arguments such as: (a) the phenomena of interest rarely have a single cause; (b) causes operate, generally, in combinations; (c) different causal combinations may produce the same result; and (d) a specific causal attribute may have different, or even opposite effects, depending on the context (Greckhamer et al., 2008; Rihoux, 2006). From this perspective, it is not assumed that effects are independently generated. On the contrary, each studied case is considered as a complex entity, being seen as a configuration of attributes which must be analyzed altogether in order to maintain case integrity (Rihoux, 2006). From this point of view, systematic comparisons between cases which present a same result of interest may be proceeded, envisaging to identify the attributes (individual or combined) which could be interpreted as common causal conditions of the result shared by the cases (Greckhamer et al., 2008). These holistic causal comparisons are performed through Boolean algebra, which is mainly characterized by the use of (a) binary data; (b) combinatory logic; (c) Boolean operators; and (d) Boolean minimization (Fiss, 2007; Ragin, 1987, 2000). Together, these properties allow the parsimonious description of complex causal relationships in the form of minimal Boolean expressions sufficient for the occurrence of a given result (Greckhamer et al., 2008; Rihoux, 2006).

Therefore, QCA was adopted as the methodological approach for the empirical research, once it is rooted in the configurational perspective and have been pointed out - in a recent literature review of research methodology in strategic management (Ketchen, Boyd and Bergh, 2008; Venkatraman, 2008) - as one of the most promising alternatives for studying organizational performance.

\section{Definition of the Result of Interest}

Having in mind the research objective, the result of interest, in general terms, is the initial PIASOs performance. Specifically, the attainment or not $^{7}$ of investments to finalize the technological (i.e. of product and/or process) and commercial development (i.e. business planning) and to launch the company was defined as the operational way by which this result would be evaluated. In spite of not considering several aspects under which the initial performance of these embryonic firms may be analyzed, this proposal has solid empirical support (e.g. Ndonzuau et al., 2002; Vohora et al., 2004).

\footnotetext{
${ }^{3} \mathrm{~A}$ property space is formed by all the possible combinations (from a logical point of view) of causal attributes of a given result of interest, including both those which are empirically observed and those which are not (Greckhamer et al., 2008).

${ }^{4}$ The term "qualitative" is used by Ragin (1987) to indicate: that QCA enables the researcher to analyze phenomena which vary in nature - i.e. which are present or absent - and not only in degree; that each case is considered as a specific attribute combination; that QCA enables the examination of constellations, configurations and conjunctures.

${ }^{5}$ I.e., populations limited, naturally or purposefully, in the number of research objects (Rihoux, 2006).

${ }^{6}$ Despite the QCA terminology invokes, conceptually, ideas as causality, the approach "[...] serves to provide empirical evidence that may or may not support causal inferences based in theory. [...] similar to investigations conducted with linear statistical methodologies, proving causality with QCA remains elusive; inferences regarding causal relationships are based on theory”. (Greckhamer et al., 2008, p. 724.) ${ }^{7}$ Reminding that the Boolean explanatory expressions, with highest parsimony, of the cases associated to one of these results of interest are not, necessarily, the negation of those obtained for the other.
} 


\section{Definition of the Attributes}

Operationally, once the result of interest is the attainment or not of initial investments by the PIASOs, it is necessary to select attributes which, based on theoretical perspectives and/or empirical evidences, are considered causal in relation to this result. In this context, once they represent the proposal most specifically aligned to this purpose, the eight variables adopted in the model presented by De Coster and Butler (2005) were defined as the attributes to be taken into consideration in the research, being supposed, a priori, causally related to the initial input (or not) of resources in PIASOs.

\section{Case Selection and Data Collection}

Once the result of interest and the causal attributes to be taken into consideration were defined, it was necessary to select the cases which would be analyzed in terms of these variables. Because they were assessed by specialist committees in the eight criteria proposed by De Coster and Butler (2005) and because they have (or have not) received an initial financial and managerial resource investment based on this evaluation, the 8I PIASOs participants of the first edition of PII at the Brazilian universities of Juiz de Fora (UFJF), Itajubá (UNIFEI), Viçosa (UFV) and Minas Gerais (UFMG) were chosen as the cases to be studied.

Indeed, in Minas Gerais State (MG), PII (an initiative of the State Secretary of Science, Technology and Superior Education of Minas Gerais, SECTES-MG, in partnership with the Brazilian Support Service for Micro and Small Companies of Minas Gerais, SEBRAE-MG, with Institutions of Science and Technology - ISTs - established in the State's cities and with the respective city halls) has been the main governmental mechanism to promote the arising of ASOs. This program aims to promote technological innovation from academic institutions of MG leading to technology protection and transfer trough licensing or, preferably, through the creation of new ventures.

The financial and managerial support to innovative projects existing in these ISTs is the foundation of PII. Based on this incentive, it aims to give support to the development of documents (e.g. business plans) and tests, prototypes and production scale-ups which facilitate technology protection and transfer, allowing to categorize the program, therefore, as a pre-incubation mechanism
(Ndonzuau et al., 2002; Vohora et al., 2004). From this perspective, all projects - including those for which the original intention is licensing - are considered as potential spin-offs. The underlying premise is that the technical and commercial studies and developments performed during the pre-incubation stage may lead to switching the preferred transfer model to the one of starting a new business (Druilhe and Garnsey, 2004).

Moreover, once the support is granted (or not) based on a structured decision making methodology grounded in the model proposed by De Coster and Butler (2005), the databases generated by the assessment committees in each IST are specially adequate for this research. These databases include the scores given by each evaluator in each IST to each project of new venture in each of the eight variables.

In all institutions, 20 projects were assessed, except for UFV, in which 21 were analyzed. Due to the guidelines established by the investors, at least half of the projects had to be supported in each institution. Hence, in all universities, approximately 10 of the PIASOs received a resource investment (in UFMG, exactly 10 received and 10 did not; at UFV the proportion was II to I0; at UNIFEI, II to 9; and at UFJF, 12 to 8 ).

The assessments were performed in March/2008 at UFJF, in April of the same year at UNIFEI, in January/2009 at UFV and in September of the same year at UFMG. From one university to another, the group of specialists varied both in size (being, at minimum, 4 members - at UFMG - and, at maximum, 9 - at UFJF), and in composition - involving always, however, at least one representative of each investing institution (i.e. SECTES-MG, SEBRAE-MG and IST).

Each evaluator gave his scores in separate, in an uneven scale from I to 9, based on conditional rules transmitted to all specialists - inspired on the rules proposed in the model of De Coster and Butler (2005). In order to subsidize the judgment in relation to these conditions, the scores were given based on the analysis of (summaries of) the projects' feasibility studies elaborated during four months in each university by a team of consultants. Both the structure and content expected in each section of the documents were standardized for all cases, so that comparative assessment would be possible.

Because the investment was done by public institutions (SECTES-MG and ISTs) and by public-oriented institu- 
tions (SEBRAE-MG), two new criteria were considered necessary to supplement the ones used by De Coster and Butler (2005) to support private investment decision: the potential for contributing to the State's development ${ }^{8}$ and the environmental impact of the new venture. Considering the new set of ten variables, a dispersion measure was calculated for each project, in order to assess its balance among the criteria.

Furthermore, projects were evaluated in terms of their development stage and their economic-financial feasibility. However, in both cases, although the scores have been given based on attempts to preserve some satisfying level of objectivity (PIASOs' stage-models and quantitative potential analysis for return on investment), the assessment had an inevitably more subjective character and was not performed by the specialist committees, but by the own consultant teams.

Treatment of the obtained data was done based on an ordering algorithm and on bubble diagrams built upon centrality and dispersion measures of the projects. The final results emerged from a discussion by the specialists about the outputs of the decision support system, not corresponding necessarily, however, to the initial classification suggested.

This methodology adopted in PII for evaluating potential high-tech start-ups is described, in its consolidated form, by Coelho (2008), and this paper's authors had complete access to the program's databases.

Therefore, given the amount of PIASOs involved, data accessibility and, mainly, the fact that the scores were given in terms of the result of interest and of the attributes chosen in this research, these embryonic ventures participants of PII were defined as the cases to be studied.

\section{Breakpoints Calibration}

In order to associate each case to a logically possible configuration in the property space to be built, it is necessary to establish, in advance, the rules to be adopted for defining the cases' membership in each attribute taken into consideration and in the chosen result of interest (i.e. calibrate breakpoints). In what regards the result of interest, once there are no level differences between the resources attained by different companies in which the program invested (i.e. all which obtain an investment, obtain it in the same quantity), the variable called "Investment by PII" - InvPII - may itself be defined as Boolean, so that receiving or not the investment is the rule for differentiating membership (i.e. InvPII=I, if the project received investment by PII; InvPII=0, if it did not).

In relation to the attributes, this simplification is not possible, once these variables were assessed in an uneven scale from I to 9. Thus, there is the possibility (confirmed by the data) that different projects would present level differences (i.e. not only type differences). Hence, for each attribute taken into consideration, it should be calibrated a breakpoint which would differentiate, satisfactorily, projects pertaining and projects not pertaining to the set defined by that dimension. For the variable called "competitive advantage protection", for example, it would be necessary to establish a breakpoint in relation to which the project's competitive advantage could be considered protected (i.e. project pertaining to the variable domain) or not.

Due to the fact that the institutions financing the program determined that at least half of the projects evaluated in each IST had to be approved in consistency with the given scores, the most natural breakpoint - which would be the average of evaluators' scores ${ }^{9}$ equal to the scale's center point (i.e. 5), could not be used. Thus, a performance measure related to the other projects of one IST (and not to the absolute performance neither to the performance related to other ISTs' projects) would have to be chosen. Once the expected approval rate was, a priori, half of the cases in all universities - consistently with the scores -, the scores' median ${ }^{10}$ of the projects in each attribute was adopted as the breakpoint in each variable in each IST. Thus, in a given university, if the project's average score was lower than the median of the average scores in a given attribute, the value of its membership in this attribute would be zero (0); otherwise, it would be one (I).

\footnotetext{
${ }^{8}$ Defined as a dimension which is distinct from the others, focused on the project's social impact.

9 Data which was used by the specialist committees themselves as the main basis for the final discussions about the projects to be approved or reproved. ${ }^{10}$ I.e. of the evaluators' average scores for each project in each attribute.
} 
For the situation in which the average score of one or more cases was equal to the median, minimal changes were made according to the premise (established by the investors) of consistency between decision and specialist scores, such that, if the project had InvPII=I, its membership to the criteria would also be I; otherwise, it would be 0 . Thus, in situations where all the projects which had an average score equal to the median also had InvPII $=0$, none value was altered - because the software used (Cronqvist, 2007) attributes zero to the values equal to the respective median. On the other hand, in situations where all the projects which had an average score equal to the median also had InvPII=I, the breakpoint was lowered in one (I) tenth in relation to the median. Lastly, in situations in which there were both projects with InvPII $=0$ and others with InvPII=I, the breakpoint was also lowered in one (I) tenth in relation to the median, but it was also done to all the average scores of all projects which had an average score equal to the median and which had InvPII $=0$.

\section{Membership Assessment}

By following these procedures, the original databases could be transformed into dichotomous assessments of case membership to each variable. Hence, it was possible to build, for each university, the property space with its $2^{8}$ (i.e. 256) logically possible configurations and with the frequency of occurrence of correspondent cases.

\section{Configurational Analyses}

Based on the constructed property spaces, a series of analyses was performed aiming to obtain, under a configurational perspective, parsimonious determinants of the differences in the capacity of PIASOs to obtain initial financial and managerial resources.

First, an analysis taking as attributes the eight variables initially selected from the study by De Coster and Butler (2005) was performed. Based on the obtained results, the other two criteria related to the projects' socio-environmental impact had to be included in order to eliminate contradiction" in the property space of any university.
Therefore, new analyses were performed from the new set of ten attributes, leading to the finding, for each IST, of the most parsimonious configurations to explain the totality of the respective cases ${ }^{12}$.

Supplementing this contextualist approach focused on PIASOs of each university, analyses were also performed aiming to obtain solutions which were able to explain, with parsimony, $100 \%$ of the $8 \mathrm{I}$ cases which were studied (i.e. investments received or not). First, an integrated database was used in order to perform this analysis, including all the cases of all ISTs in a single property space. However, once the obtained results were not satisfactory, the analysis of each university separately, followed by the comparison between the solutions, was the methodological alternative adopted.

Ideally, these comparative analyses should be done for all possible subsets of the ten attributes set, in order to go through all possible solution. However, given the impossibility to do this scanning with current software, we performed exploratory analyses, from the selection, grounded in heuristics based on the available data, of some few subsets of variables with distinctive potential to explain all 81 cases. The following analyses were performed: exploratory analyses based on the most parsimonious configurations for explaining the cases at each university (analyses from subsets of variables selected amongst the subsets used by the most parsimonious configurations of each university themselves; and analyses from subsets of variables selected based on the occurrence of the attributes in the subsets used by the most parsimonious configurations of each university); and exploratory analyses from subsets selected based on the weights given to the criteria by PII specialist committees.

\section{Results}

The results achieved from the various analyses performed are summarized in Figure 2, which points to the contribution of the obtained empirical evidences to grounding new propositions which refine the state-of-art of the research on the determinants of PIASOs' initial performance.

\footnotetext{
"At least two cases associated to one same attribute configuration, but to different results of interest.

${ }^{12}$ This corroborates the premise of consistency between decision made and evaluation in the adopted criteria.
} 


\begin{tabular}{|c|c|c|c|}
\hline \multicolumn{2}{|c|}{ Analysis } & Result & Proposition \\
\hline \multirow{9}{*}{ 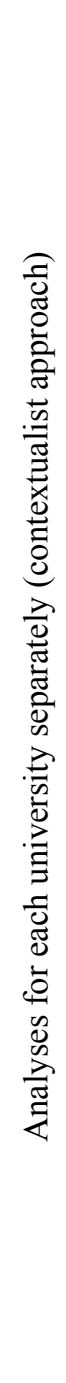 } & \multirow{2}{*}{$\begin{array}{l}\text { Analysis based on the } 8 \\
\text { attributes }\end{array}$} & $\begin{array}{l}\text { Few contradictions (only between } 2 \\
\text { cases at UFV and between } 3 \text { at UFJF) }\end{array}$ & $\begin{array}{l}\text { The } 8 \text { criteria presented by De Coster and Butler (2005) for assessing } \\
\text { technology-based new ventures in order to support the investment decision are } \\
\text { sufficient for explaining, in great part, the attainment or not of an initial } \\
\text { investment by the PIASOs }\end{array}$ \\
\hline & & $\begin{array}{l}\text { Demand, in order to explain all cases } \\
\text { (i.e. contradiction elimination), to } \\
\text { include the variables State } \\
\text { Development and Environmental } \\
\text { Impact in the attribute set }\end{array}$ & $\begin{array}{l}\text { When dealing with public investors, variables related to the socio-environmental } \\
\text { impact of the embryonic firm are necessary to explain the initial investment (or } \\
\text { non-investment) in PIASOs }\end{array}$ \\
\hline & $\begin{array}{l}\text { Analysis based on the new } \\
\text { set of } 10 \text { attributes, without } \\
\text { including the remainders }{ }^{13} \\
\text { for simplification }\end{array}$ & $\begin{array}{l}\text { For each university, configurations } \\
\text { explained all respective cases }\end{array}$ & $\begin{array}{l}\text { The } 8 \text { criteria presented by De Coster and Butler (2005) supplemented by } \\
\text { variables related to the socio-environmental impact of the new ventures are } \\
\text { sufficient to explain the attainment or not of an initial investment by the PIASOs }\end{array}$ \\
\hline & \multirow{6}{*}{$\begin{array}{l}\text { Analysis based on the new } \\
\text { set of } 10 \text { attributes, } \\
\text { including the remainders for } \\
\text { simplification }\end{array}$} & \multirow{6}{*}{$\begin{array}{l}\text { For each university, the most } \\
\text { parsimonious configurations } \\
\text { explained all respective cases }\end{array}$} & $\begin{array}{l}\text { Generally, more than one variable is necessary to explain, in the most } \\
\text { parsimonious way, the initial investment (or non-investment) in PIASOs (i.e. the } \\
\text { causality is multiple) }\end{array}$ \\
\hline & & & $\begin{array}{l}\text { The most parsimonious configurations (i.e. variable combinations) of the initial } \\
\text { investment (or non-investment) in PIASOs are strongly context-dependent (i.e. } \\
\text { university) }\end{array}$ \\
\hline & & & $\begin{array}{l}\text { For one same context (i.e. university), different configurations may explain, with } \\
\text { the same parsimony, the initial investment (or non-investment) in PIASOs }\end{array}$ \\
\hline & & & $\begin{array}{l}\text { The behavior of a given variable may be associated to different effects, } \\
\text { depending on the behavior of the other variables (i.e. the causality is } \\
\text { conjuncture-dependent) }\end{array}$ \\
\hline & & & $\begin{array}{l}\text { The configurations which explain, with most parsimony, the initial non- } \\
\text { investment in PIASOs are not, necessarily, the negation of the configurations } \\
\text { which explain, with most parsimony, the initial investment }\end{array}$ \\
\hline & & & $\begin{array}{l}\text { When dealing with public investors, variables related to the impact of the new } \\
\text { venture in State development is an important variable for explaining the initial } \\
\text { investment (or non-investment) in PIASOs }\end{array}$ \\
\hline
\end{tabular}

${ }^{13}$ Logical configurations for which there was no empirical correspondence. 


\begin{tabular}{|c|c|c|c|}
\hline \multirow{4}{*}{ 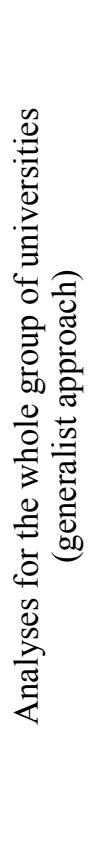 } & \multirow{4}{*}{$\begin{array}{l}\text { Analyses from each } \\
\text { university database } \\
\text { separately }\end{array}$} & \multirow{4}{*}{$\begin{array}{l}\text { Subsets of three to five of the ten } \\
\text { attributes used explained, even though } \\
\text { through different configurations for } \\
\text { each context, the totality (or, at least, } \\
\text { a great part) of the invested and non- } \\
\text { invested cases }\end{array}$} & $\begin{array}{l}\text { Although the configurations through which the initial investment (or non- } \\
\text { investment) in PIASOs is explained are strongly context-dependent, there are } \\
\text { inter-contextual regularities in what regards subsets os variables (more } \\
\text { parsimonious than the ten attribute set) whose combinations (i.e. of variables) } \\
\text { explain the totality (or, at least, a great part) of the invested and non-invested } \\
\text { cases }\end{array}$ \\
\hline & & & $\begin{array}{l}\text { Configurations of the (5) following variables - technological and commercial } \\
\text { risk, level of product innovation, existence of product family, entrepreneurial } \\
\text { background and potential to contribute to State development - are sufficient to } \\
\text { explain the initial investment (or non-investment) in PIASOs }\end{array}$ \\
\hline & & & $\begin{array}{l}\text { Configurations of the (4) following variables - technological and commercial } \\
\text { risk, level of product innovation, way of satisfying the market sector and } \\
\text { potential to contributing to State development - are sufficient, in great } \\
\text { measure }{ }^{14} \text {, to explain the initial investment (or non-investment) in PIASOs }\end{array}$ \\
\hline & & & $\begin{array}{l}\text { Configurations of the (3) following variables - level of product innovation, way } \\
\text { of satisfying the market sector and potential to contributing to State development } \\
\text { - are sufficient, in great measure }{ }^{15} \text {, to explain the initial investment (or non- } \\
\text { investment) in PIASOs }\end{array}$ \\
\hline
\end{tabular}

Figure 2. Propositions inferred based on the results obtained from the analyses performed. Elaborated by the authors.

${ }^{14}$ Explanation, in average, of $95 \%$ of the cases (invested and not invested).

${ }^{15}$ Explanation, in average, of $88 \%$ of the invested cases and $83 \%$ of the non-invested cases. 
Therefore, as emphasized in Figure 2, the general objective and the specific objectives of the work were fulfilled. The analyses performed supplied both the identification (from a configurational perspective) of parsimonious determinants of PIASOs' initial performance, the characterization of the causal complexity of configurations which explain this result of interest and the assessment of the explanatory power of attributes held as references in the related academic literature.

In what regards this evaluation, the high potential of the eight criteria proposed by De Coster and Butler (2005) to explain PIASOs' initial performance was evidenced, but also their limitation for explaining some cases in the public investment context, due to the non-inclusion of variables related to the socio-environmental impact of the new ventures. Indeed, the potential to contribute to the State's development revealed itself as an attribute of great importance, in general, for explaining, in the most parsimonious way possible, whether these embryonic firms obtained or not an initial investment.

On the other hand, in what regards the characterization of the causal complexity of those configurations which were found, the research reinforced the notion of causality assumed by the configurational perspective, showing that, indeed, multiple variables, with interdependent behaviors, may produce, in different ways, the same combined effect.

The only solution obtained for UFJF in the analysis of InvPII=I, for example, consisted in a configuration of three attributes combined in double two-size terms: PotTec $\{\mid\} \mid$ novProdConc $\{0\}+$ InovProdConc $\{\mid\} \operatorname{DesEst}\{\mid\}$. This expression, which explains in the smallest form possible $100 \%$ of the approved cases, could be interpreted as follows: as long as the project has technological potential to overcome risks (PotTec) but is not innovative (InovProdConc), or is innovative and contributes to the State's development (DesEst), it was approved at UFJF.

A configuration involving these same variables, in an expression also of double two-size terms, was obtained to explain the cases which presented InvPII=0: PotTec $\{0\}$ InovProdConc $\{0\}+\operatorname{InovProdConc}\{\mid\}$ DesEst $\{0\}$. This could be interpreted as follows: as long as the PIASO has not technological potential nor is innovative, or is innovative but does not contribute to the State's development (DesEst), it was not approved at UFJF.
These two configurations, one for each value of the result of interest, illustrate the QCA's relevance for refining the understanding of the way through which the causality of a given effect is configured as multiple and dependent on the contextual conjuncture. These Boolean expressions give evidence to the fact that a single behavior in one variable (e.g. at InovProdConc) may lead to different results depending on the behavior of the cases in other attributes.

Similarly, the proposition that a same effect may be caused by different causal conditions is reinforced by the other five resultant expressions, the most parsimonious possible, to explain the cases for which InvPII $=0$. Along with the expression which used the same three variables of the solution obtained for the other result of interest (i.e. InvPII=I), we found, also, these other configurations (of the same size and amount of terms), each one comprising distinct sets of four variables, including other attributes not yet considered in this IST solutions. This variety indicates a higher versatility, in relation to the approved cases, based on the existing data, for explaining, in the smallest form possible, the projects reproved at this university.

These results reinforce, therefore, limitations of the approaches based on the analysis of isolated independent effects and the relevance of the notion of configuration for the research on organizational performance.

Lastly, the performed analyses allowed the identification of parsimonious determinants of PIASOs performance. As it was mentioned in Figure 2, the configurations explaining the cases associated to a given result of interest formed by variables of a given subset of the set of ten attributes were strongly context-dependent, hindering the identification of valid parsimonious Boolean expressions which could explain most of the $8 \mathrm{I}$ cases of all ISTs. However, as it was emphasized "there are inter-contextual regularities in what regards subsets of variables (more parsimonious than the ten attribute set) whose combinations (i.e. of variables) explain the totality (or, at least, a great part) of the invested and noninvested cases". Thus, even though it was not possible to highlight parsimonious determinants of the PIASOs' initial performance at the configuration level, it was possible to identify some of them in terms of subsets of more parsimonious variables than the original criteria set. 
Considering the logical principle known as "Occam's Razor", this empirical finding has a special relevance, once it highlights the possibility of explaining a phenomenon in a more parsimonious way than the existent alternatives. Therefore, although the subsets of variables came from an exploratory study, they serve as a basis for grounding future research in the area, which may explore the explanatory potential of these attribute sets in other contexts, contributing to gradually refine the understanding of PIASOs' initial performance.

\section{Conclusion}

In this section, we formulate this paper's final considerations, emphasizing its main contributions and summarizing the opportunities for refining the research and the suggestions for future papers which aim to develop this topic of study.

\section{Contributions}

We conclude that this research presents a distinctive contribution of a methodological nature, as it consists in one of the first applications of the qualitative comparative analysis in the field of strategic management - pioneer ${ }^{16}$ in the study of academic spin-offs -, illustrating, through a concrete example, the configurational perspective's contribution for refining the investigation about the determinant factors of organizational performance heterogeneity.

Differently from the sole similar work found at the strategic management literature (Greckhamer et al., 2008), the empirical research which was performed involved a small case set and a relatively large attribute set, giving an operational reference of the manner through which methodological artifices may be developed in order to overcomethelimitationsfound when theuse ofQCAhappens under these circumstances. Specially, the exploratory procedures for selecting attribute subsets illustrate ways through which satisfactorily grounded heuristics may be proposed for prioritizing alternative analysis routes when exploring all the possibilities is not possible.

\footnotetext{
${ }^{16}$ To the authors' best knowledge.
}

Beyond these methodological developments, however, substantive contributions were also achieved. Among these, we emphasize the attainment of subsets of variables which explain, with considerably superior parsimony, the same result of interest. Furthermore, it was also evidenced the causal complexity underlying performance differences among academic spin-offs. The results pointed, for example, to the possibility of having distinct effects depending on the behavior of other attributes and of explaining failure by others means than those used to explain success. Lastly, it was also shown that, for public investments, in comparison to private ones, there are non-despicable differences in the criteria which are necessary to explain the attainment or not of resources by the evaluated project. Therefore, we expect that this paper contributes to both methodology and theory, serving as reference for future academic researches.

For the managerial practice and the orientation of public policies, however, this paper's relevance is still limited. More substantial contributions may be generated in the future from longitudinal studies which relate characteristics of the projects in which there was an investment with the subsequent performance of the respective companies in the market. This extended vision may supply the investor with a more consistent basis to focus his start-up assessments in just a few dimensions whose combinations shall determine, in great part, the firm's success or failure.

Up to now, however, the fact that we found parsimonious subsets which explain the investment (and the non-investment) at the four studied universities is not sufficient to affirm that the other criteria are not necessary to evaluate PIASOs projects. After all, (a posteriori) explanations do not necessarily enable future (a priori) forecasts.

\section{Research refinement opportunities and suggestions for future papers}

Although this research represents a pioneering methodological initiative in the study of explanatory factors of academic spin-offs' performance, it presents some refinement opportunities, from which several suggestions may be given for future papers which aim to develop the perspective introduced in this paper (Figure 3). 


\begin{tabular}{|c|c|c|}
\hline & Research refinement opportunity & Suggestion for future papers \\
\hline \multirow{2}{*}{$\begin{array}{l}\text { Definition of } \\
\text { the result of } \\
\text { interest }\end{array}$} & $\begin{array}{l}\text { High specificity of the chosen result of interest (i.e. among the } \\
\text { academic spin-offs, only those pre-incubated; as to the } \\
\text { performance, only the initial one) }\end{array}$ & $\begin{array}{l}\text { Definition of broader results of interest } \\
\text { (e.g. academic spin-offs performance, } \\
\text { in general) }\end{array}$ \\
\hline & $\begin{array}{l}\text { Desconsideration of several aspects (apart from obtaining or } \\
\text { not an investment) by which the initial performance of pre- } \\
\text { incubated academic spin-offs may be evaluated }\end{array}$ & $\begin{array}{l}\text { Evaluation of academic spin-offs } \\
\text { performance from other perspectives, } \\
\text { and not only investment attainment }\end{array}$ \\
\hline $\begin{array}{l}\text { Definition of } \\
\text { the attributes }\end{array}$ & $\begin{array}{l}\text { Limitation to the criteria utilized in the model presented by De } \\
\text { Coster and Butler (2005) }\end{array}$ & $\begin{array}{l}\text { Use of other empirical and/or } \\
\text { theoretical base for defining the } \\
\text { attributes }\end{array}$ \\
\hline \multirow{3}{*}{$\begin{array}{l}\text { Case selection } \\
\text { and data } \\
\text { collection }\end{array}$} & Limitation to cases in the State of Minas Gerais & Selection of cases from other locations \\
\hline & $\begin{array}{l}\text { Limitation of the database's adequacy to the research due to } \\
\text { the variation, among universities, in the size and composition } \\
\text { of the specialist groups evaluating the projects }\end{array}$ & \multirow{3}{*}{$\begin{array}{l}\text { Building databases specifically } \\
\text { adequate to the proposed analyses }\end{array}$} \\
\hline & $\begin{array}{l}\text { Inexistence, at the UFJF database, of separate grades for the } \\
\text { two variables related to the project's socio-environmental } \\
\text { impact }\end{array}$ & \\
\hline \multirow{4}{*}{$\begin{array}{l}\text { Breakpoints } \\
\text { calibration and } \\
\text { membership } \\
\text { assessment }\end{array}$} & $\begin{array}{l}\text { Limitation of the database's adequacy to the research due to } \\
\text { the imposition, in the Innovation Promotion Program, of the } \\
\text { rule which establishes the approval of at least half of the } \\
\text { projects evaluated at each university }\end{array}$ & \\
\hline & Limitation to the use of dichotomous variables (i.e. 0 or 1 ) & $\begin{array}{l}\text { Use of fuzzy and multivalue variables } \\
\text { for evaluating membership }\end{array}$ \\
\hline & $\begin{array}{l}\text { Use of the evaluators' average scores as original data and use } \\
\text { of the projects' average scores median in a given attribute for } \\
\text { calibrating the breakpoints in all universities }\end{array}$ & $\begin{array}{l}\text { Analyzing the sensibility of this } \\
\text { research's results to changes in } \\
\text { breakpoint calibration }\end{array}$ \\
\hline & $\begin{array}{l}\text { Use of the attainment or not of an initial investment as a } \\
\text { parameter for distinction of the cases whose average score } \\
\text { were equal to the breakpoint in a given attribute }\end{array}$ & $\begin{array}{l}\text { Analyzing the sensibility of this } \\
\text { research's results to other forms of } \\
\text { distinction of these cases (e.g. through } \\
\text { similarity in the other attributes) }\end{array}$ \\
\hline \multirow{2}{*}{ Analyses } & $\begin{array}{l}\text { Impossibility to test all the subsets of the ten attributes set due } \\
\text { to the inexistence of an appropriate computational tool, what } \\
\text { required the performance of analyses of an exploratory nature }\end{array}$ & $\begin{array}{l}\text { Development of a computational tool } \\
\text { for the automatic performance, in large } \\
\text { scale, of tests and result comparison }\end{array}$ \\
\hline & $\begin{array}{l}\text { Use of configurations resulting from analyses including } \\
\text { remainders for simplification as a basis for determining rules } \\
\text { for selecting subsets to be tested in a exploratory manner }\end{array}$ & $\begin{array}{l}\text { Development of alternative heuristics } \\
\text { for selecting the attribute subsets and } \\
\text { refining the treatment of remainders }\end{array}$ \\
\hline
\end{tabular}

Figure 3. Research refinement opportunities and suggestions for future papers. Elaborated by the authors.

As it may be observed in Figure 3, although an explicit effort was made towards controlling the error of the research conclusions, there are some refinement possibilities. Specially, the adoption of secondary data generated by the Innovation Promotion Program brought some complications both for constructing the property space and for performing the analyses. Furthermore, the conclusions which were obtained are restricted to a considerably specific result of interest, and its empirical relevance is limited. Lastly, sensibility analyses of the results to different methodological decisions which could refine the obtained results' status are suggested as research opportunities for future work.
Indeed, beyond these refinements, the exploration of the use of configurational comparative methods, in general, and of QCA, in particular, for developing the research in technology and innovation management remains, in accordance with claims made by Greckhamer et al. (2008), Ketchen et al. (2008) and Venkatraman (2008), as this paper's main suggestion. As exemplified by the investigation performed, the differences between technology-based innovative organizations have much more complex explanations than the analysis of contingent relations resulting from the application of linear statistical methodologies may indicate. It is time, therefore, for our methodological approaches to tackle appropriately the causal complexity that characterizes the phenomena we are most interested in. 


\section{References}

BARNEY, J.B. (199I). Firm resources and sustained competitive advantage. Journal of Management, I7, 99-120.

COELHO, B.F.P. (2008). Desenvolvimento de um processo de decisão para classificação de projetos tecnológicos apoiados pelo Programa de Incentivo à Inovação (PII). Trabalho de Graduação, Universidade Federal de Minas Gerais, Belo Horizonte, MG, Brasil.

CRONQVIST, L. (2007). Tosmana - Tool for Small-N Analysis (Version I.3). [Software]. Marburg. http://www. tosmana.net [Accessed September 10, 2009].

DE COSTER, R., Butler, C. (2005). Assessment of proposals for new technology ventures in the UK: characteristics of university spin-off companies. Technovation, 25, 535-543.

DJOKOVIC, D., Souitaris, V. (2008). Spinouts from academic institutions. Aliterature review with suggestions for further research. Journal of Technology Transfer, 33, 225-247.

DRUILHE, C., Garnsey, E. (2004). Do academic spin-outs differ and does it matter? Journal of Technology Transfer, 29(3-4), 269-285.

FISS, P. (2007). Towards a set-theoretic approach for studying organizational configurations. Academy of Management Review, 32(4), I180-1198.

GONÇALVES, C.A., Muniz, R.M., Freitas, J.S., Cheng, L.C. (2009). Modelo para avaliação de desempenho organizacional: Uma proposta para orientação da pesquisa entre Brasil e União Européia na área de estratégia. In: Silva, J.R., Barbosa, A.C.Q. (Eds.) Estado, Empresas e Sociedade: Um Mosaico Luso-Brasileiro. Edições Colibri, Lisboa. Pp. 65-102.

GRANSTRAND, O. (1998). Towards a theory of the technology-based firm. Research Policy, 27, 465-489.

GRECKHAMMER, T., Misangyi, V., Elms, H., Lacey, R. (2008). Using qualitative comparative analysis in strategic management research: An examination of combinations of industry, corporate, and business-unit effects. Organizational Research Methods, II(4), 695-726.
HERRMANN, P. (2005). Evolution of strategic management: the need for new dominant designs. International Journal of Management Reviews, 7, III-130.

HOSKISSON, R.E., Hitt, M.A., Wan, W.P., Yiu, D. (1999). Theory and research in strategic management: swings of pendulum. Journal of Management, 25, 4I7-456.

HUTZSCHENREUTER, T., Kleindienst, I. (2006). Strategy-process research: what have we learned and what is still to be explored. Journal of Management, 32, 673-720.

KAKATI, M. (2003) Success criteria in high-tech new ventures. Technovation, 23, 447-457.

KETCHEN, D.J., Boyd, B.K.Jr., Bergh, D.D. (2008). Research methodology in strategic management: past accomplishments and future challenges. Organizational Research Methods, II(4), 643-658.

KNIGHT, R. M. (1994) Criteria used by venture capitalists: a cross-cultural analysis. International Small Business Journal, I3(I), 26-37.

MACMILLAN, I.C. (1985) Criteria used by venture capitalist to evaluate new venture proposals. Journal of Business Venturing, I, I19-128.

MAHONEY, T.J., McGahan, A.M. (2007). The field of strategic management within the evolving science of strategic organization. Strategic Organization, 5(I), 79-99.

MELLAHI, K., Sminia, H. (2009). Guest Editors' Introduction: The frontiers of strategic management research. International Journal of Management Reviews, II(I), I-7.

MEYER, A. D., Tsui, A. S., Hinings, C. R. (1993). Configurational approaches to organizational analysis. Academy of Management Journal, 36, II75-1195.

MINTZBERG, H. (1973). The nature of managerial work. New York: Harper \& Row.

MINTZBERG, H., Waters, J.A. (1985). Of strategies, deliberate and emergent. Strategic Management Journal, 6, 257-272. 
MUSTAR, P., Renault, M., Colombo, M.G., Piva, E., Fontes, M., Lockett, A., Wright, M., Clarysse, B., Moray, N. (2006). Conceptualising the heterogeneity of researchbased spin-offs: A multi-dimensional taxonomy. Research Policy, 35, 289-308.

NDONZUAU, F.N., Pirnay, F., Surlemont, B. (2002). A stage model of academic spin-off creation. Technovation, 22(5), 28I-289.

O'SHEA, R.P., Chugh, H., Allen, T.J. (2008). Determinants and consequences of university spinoff activity. Journal of Technology Transfer, 33, 653-666.

RAGIN, C. C. (1987). The Comparative Method: Moving Beyond Qualitative and Quantitative Strategies. University of California Press, Berkeley, Los Angeles and London.

RAGIN, C. C. (2000). Fuzzy-Set Social Science. University of Chicago Press, Chicago.

RIHOUX, B. (2006). Qualitative comparative analysis (QCA) and related systematic comparative methods. International Sociology, 2I, 679-706.

ROBERTS, E., Eesley, C. (2009). Entrepreneurial Impact: The Role of MIT. Massachussets Institute of Technology.

ROTHAERMEL, F.T., Agung, S.D., Jiang, L. (2007). University entrepreneurship: a taxonomy of the literature. Industrial and Corporate Change, 16(4), 691-791.

SONG, M., Podoynitsyna, K., van der Bij, H., Halman, J.I.M.. (2008) Success factors in new ventures: A meta-analysis. Journal of Product Innovation Management. 25, 7-27.

VENKATRAMAN, N. (2008). Advancing strategic management insights: Why attention to methods and measurement matters. Organizational Research Methods, II(4), 790-794.

VOHORA, A., Wright, M., Lockett, A. (2004). Critical junctures in the development of university high-tech spinout companies. Research Policy, 33, 147-175.

WERNERFELT, B. (1984). A resource-based view of the firm. Strategic Management Journal, 5, I7I-180.
WHITTINGTON, R. (1996). Strategy as practice. Long Range Planning, 29, 731-735.

ZACHARAKIS, A. L., Meyer, G. D. (2000). The potential of actuarial decision models: can they improve the venture capital investment decision? Journal of Business Venturing, 15, 323-346. 
J. Technol. Manag Innov. 20II,Volume 6, Issue 2 